\title{
EFFECTTHE ELECTRICAL SHOCK ON THE HEART RATES OF HOUSE FLYMusca domestica
}

\author{
TALAL T.MAHMOUD and ViYAN G.MOHAMMAD \\ Dept. of plant protection, University of Duhok, College of Agriculture, Kurdistan Region-Iraq.
}

(Received: November 18, 2015; Accepted for publication: February 7, 2017)

\begin{abstract}
This study was carried out from March, 2013 to the end of December,2014.Including several experiments only on adult house fly, in the growth chamber ofthe Department of Plant Protection,and Central Laboratory in Faculty of Agriculture and Forestry, University of Duhok,Kurdistan Region of Iraq. The experimental flies were collected from field of the(Delbe) village $5 \mathrm{~km}$. away from the West Duhok city using the hand net, during summer of 2013.The results showed the electrical shock gave $117.60 \mathrm{~b} / \mathrm{min}$.During studying the biological phenomena after the treatment of the flies by electric shock, it was shown that the subsequent generation that was raised from insect had reduced mating process. Also it was observed that the emerged adult appeared to be handicap such sluggish with slow movement. Two days excess increased the emerged flies but the larval intervals extended to a long time and after few days the insects were unable to emerge and died, while half of their body was out of puparium.
\end{abstract}

KEYWORDS: Housefly, electrical shock, Heartbeats

\section{INTRODUCTION}

$\mathbf{H}$ ousefly, Musca domestica L. is a global species and lives in close relations to human. It is usually considered as a mechanical vector of diseases and capable to transfer hundreds of pathogenic organisms to human and animals. $M$. domestica usually attracted to human food sources or animal wastes (Nmorsietet al.,2007; Sanchez and Capinera, 2008; Butler et al., 2010 and Wikipedia, 2011). Searching in literature no work has been done on the effect of electric shock on heart activities. The aim of this study is to shed a light on the role of electric in the behavior and the heart reaction in order to find the alterations should happen in vivo of the body contents.

\section{MATERIALS AND METHODS \\ Method of Obtaining House Flies}

Experimental flies were collected from field of the (Delbe) village $5 \mathrm{~km}$. away from the west Duhok city using the hand net, during summer of 2013. This work was repeated several times to capture (100-150)flies. The flies were transferred to the laboratory, then placed in cages inside growth chamber at $27 \pm 1^{\circ} \mathrm{C}$ all flies were kept in a sleeved cage, a hole was cut front $(10 \mathrm{~cm}$ in diameter) with long sleeve $20 \mathrm{~cm}$ for daily services. The rearing containers were provided by a pair of holes (windows) in both sides ( $15 \times 20$ $\mathrm{cm}$ ), for the ventilation purposes, figure (1) (Sanchez, 1998).

\footnotetext{
*Part of M.Sc.thesis of second Author
} 


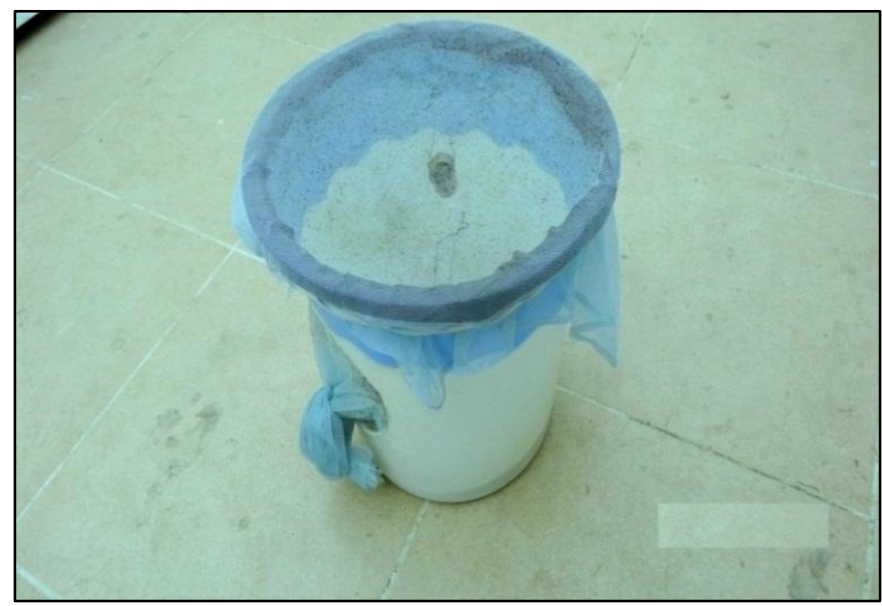

Fig. (1):

\section{Feeding Method}

Adult flies were reared in plastic cages and supplied with food which was a mixture of $10 \%$ sugar solution plus 5 drops/liter of vitamin B12 with powder milk (Kristiansen and Jespersen, 2004). The cotton wool immersed in $10 \%$ sugar solution and submitted inside small pots, and hanged inside the container in swing case. The powder milk was placed inside the small bowls in the bottom of the cages. The food was tested daily. The sugar solution $10 \%$ was prepared by dissolving 100 grams of crystalline sugar in one liter of tap water then 5 drops of vitamin B12 were added (Tawfik et al., 1974; Mahmoud, 1991; Patricia and Claudio, 2007).

\section{Rearing Method}

A plastic container $(5 \times 5 \mathrm{~cm})$ containing a bread previously immersed in meat soup and offered as oviposition sites and observed daily for the presence of eggs. Transfer the egg to rearing container, the lid and windows were closed by muslin cloth for ventilation, and prevented the larvae to escape also the other insects to pass through the container. A thick layer of sand was added to the bottom of the container to form a cooler and drier place for larvae to pupate (Sumitomo, 1997). Then the pupae still tightly sealed until the adults emergence, these newly emerged flies (first generation) were provided with $10 \%$ sugar solution, then reared in the same manner as previously described. Rearing performed at $27 \pm 1 \mathrm{C}^{\circ}, 40-50 \%$ Relative Humidity, a constant illumination of $14-10$ L: D (Kence and kence ,1993; Sharifi fard et al., 2012). The above temperature was used in all experiment.

\section{General Techniques}

Each experiment consists of 50 insects with 5 Replicates as in figure (2), three insects from each replicate were picked up using plastic hose to measured the insect heart beats, each observation took one minute interval for three times using a special hand counter (Tally Counter. UAE, Beita. No.008). Stick the fly on trap and those fixed on slide as in figure (3). Then counted the pulsing by compound microscope, observations were done on the heart through the $3^{\text {rd }}$ abdominal segment in all experiments they measured the characters; the insect movement, flying ,mating processes , mortality, paralysis, determine the threshold point and heart beating in above thermal condition. The above observations were performed after $1 \mathrm{hr}$. of exposure except that of zero degree centigrade after $5 \mathrm{~min}$. 


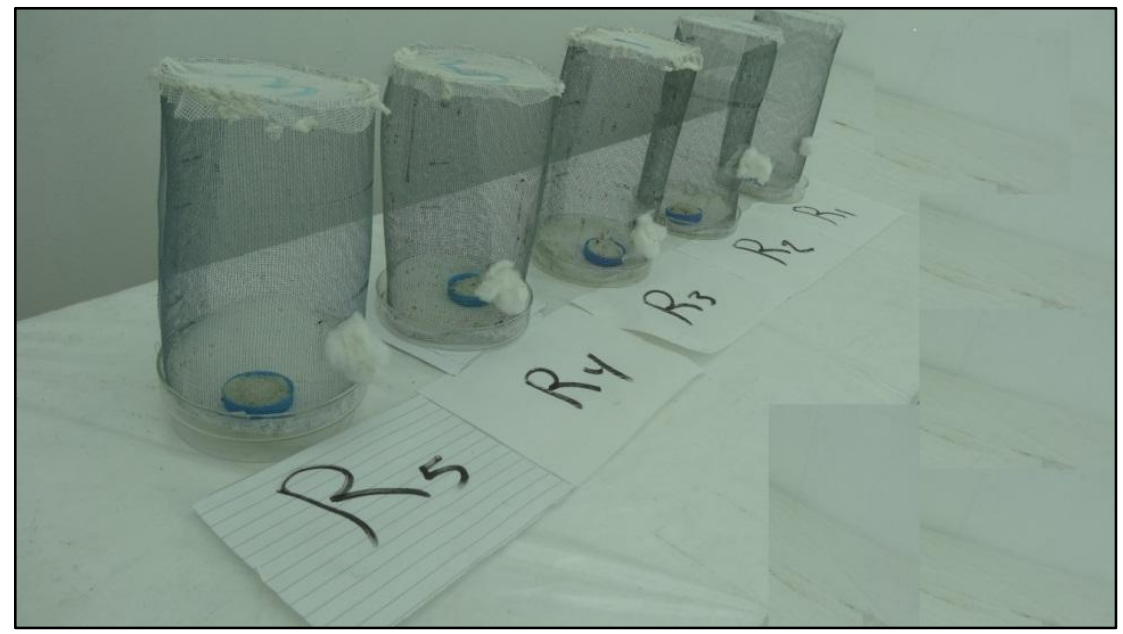

Fig. (2): Small cages for experiments of adult house flies

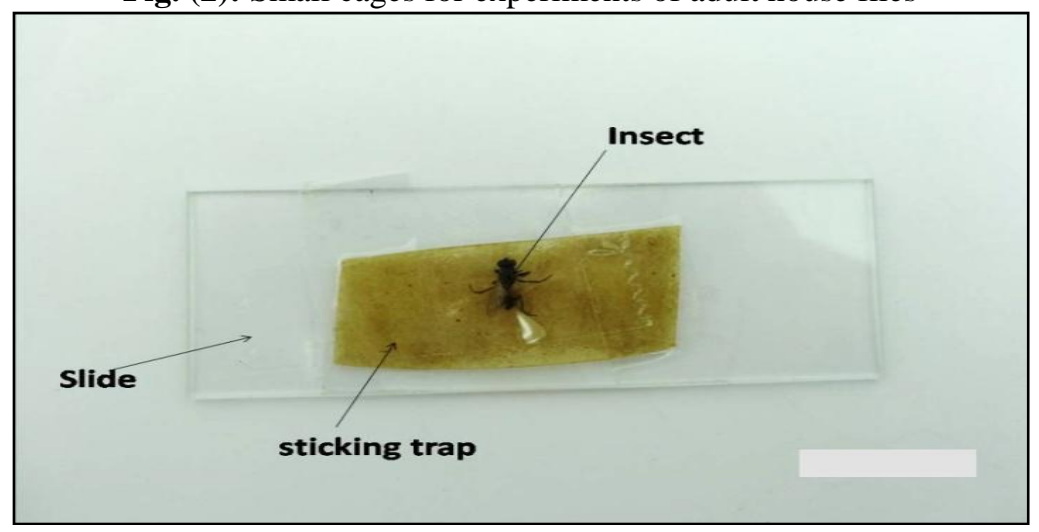

Fig. (3): The sticking trap for measuring the heart rates

\section{Electrical Shock}

This experiment was applied at temperature of $27 \pm 1^{\circ} \mathrm{C}$ and R.H. $40 \%$, the insects treated by electrical killer fly (100V-240V AC China) as in figure (4), after the fly individually shocks for 1 sec. returned to the small cages of experiment in growth chamber. Observations were taken on the following phenomena, shaking, upside down, aggregation, they measured the characters; the insect movement, flying, mating processes , mortality, paralysis , determine the threshold point and heart beating in above thermal condition. The flies were treated in three various intervals 1, 2 and 3 shocks, press of shock gave $71.3 \mathrm{kv}$, the second shock rate $71.2 \mathrm{kv}$ and third shock $0.8 \mathrm{kv}$. with same trend and one second for each replicate, and collected the data. 


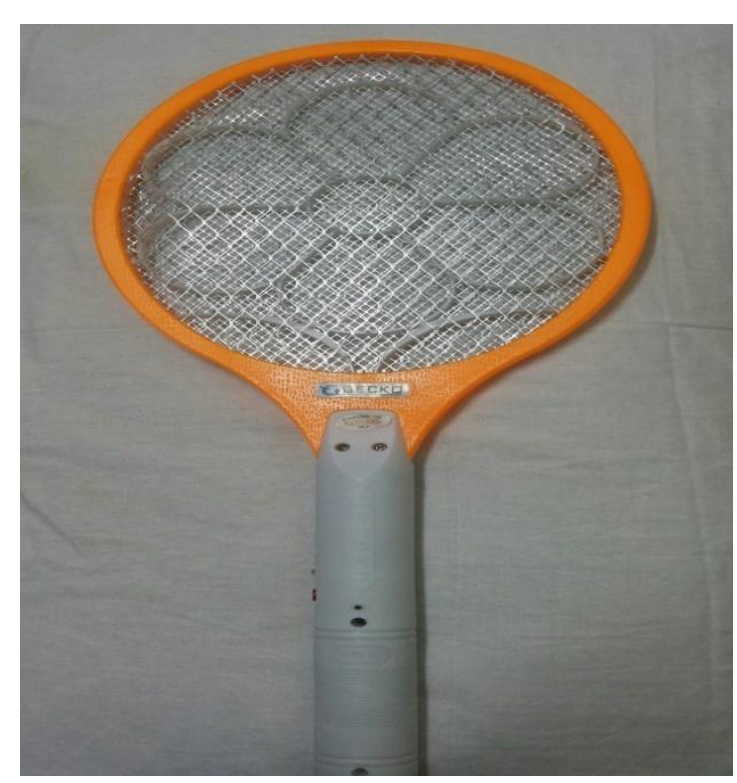

Fig. (4): Electrical killer of fly for shock experiments

\section{Histological Technique}

The circulatory system as a result was studied using the histological technique in adult including, thorax, and abdomen by making cross, and longitudinal sections, using the rotary microtome type QPJ 13001123 (China). Sections were prepared from both control and treated at $27 \pm 1^{\circ} \mathrm{C}$ electrical shock using 5 individuals in each experiment and followed the standard methods, of (Gurr, 1963; and Mahmoud, 1985, 1991, 2012). The samples were picked up from the replicates, then their wings, legs and antennae were taken off and followed the basic staining procedure (Pantin, 1964; and Mahmoud, 2012).Statistical analysis was used in this work and followed the design of randomize complete block design (RCBD), the tested mainly used the method ofaverage range Duncan test, with 5 replication.Steel, and Torric(1980).

\section{RESULT AND DISCUSSION}

The rate of heart beats gavethe maximum impuls were $119.20 \mathrm{~b} / \mathrm{min}$., while the minimum took $102.20 \mathrm{~b} / \mathrm{min}$. the treated insects moved abnormal zigzag and terrible. Also caused the Coagulated blood.

Figure (5) illustrate that the mean of hear tbeats of housefly in the first minute was $342 \mathrm{~b} / \mathrm{min}$.,in the second minute $347.8 \mathrm{~b} / \mathrm{min}$.; and in the third minute

334.2

$\mathrm{b} / \mathrm{min}$. 


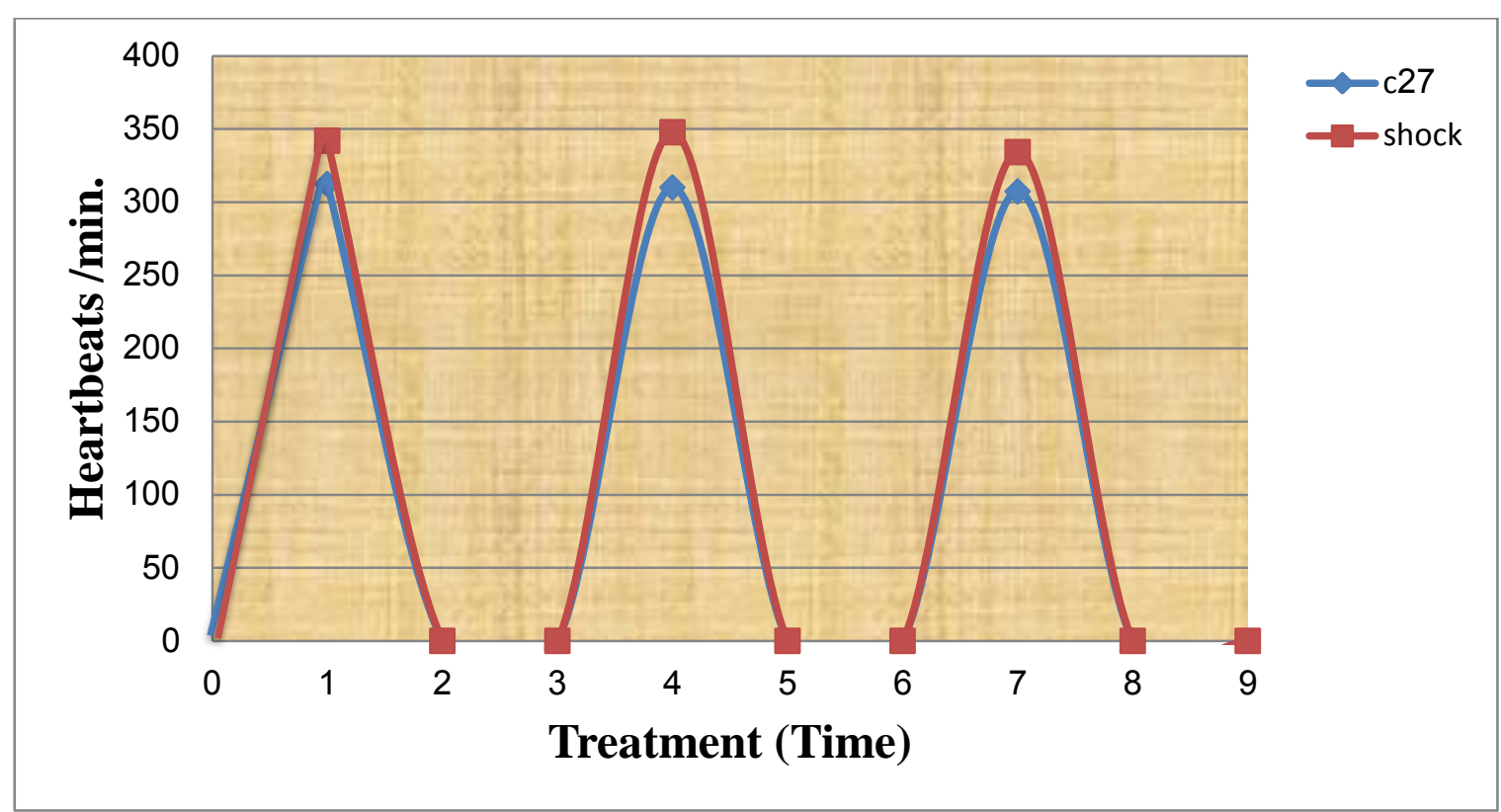

Fig. (5): The effect of electric shock on heart beats at $27 \pm 1^{\circ} \mathrm{C}$

phenomena after the treatment of the flies by electric shock, it was shown that the subsequent generation that was raised from insect had reduced mating process. Also it was observed that the emerged adult appeared to be handicap such sluggish with slow movement. Two days excess increased the emerged flies but the larvae intervals extended to a long time and after few days the insects were unable to emerge and died, while half of their body was out of puparium as shown in figure

(6).

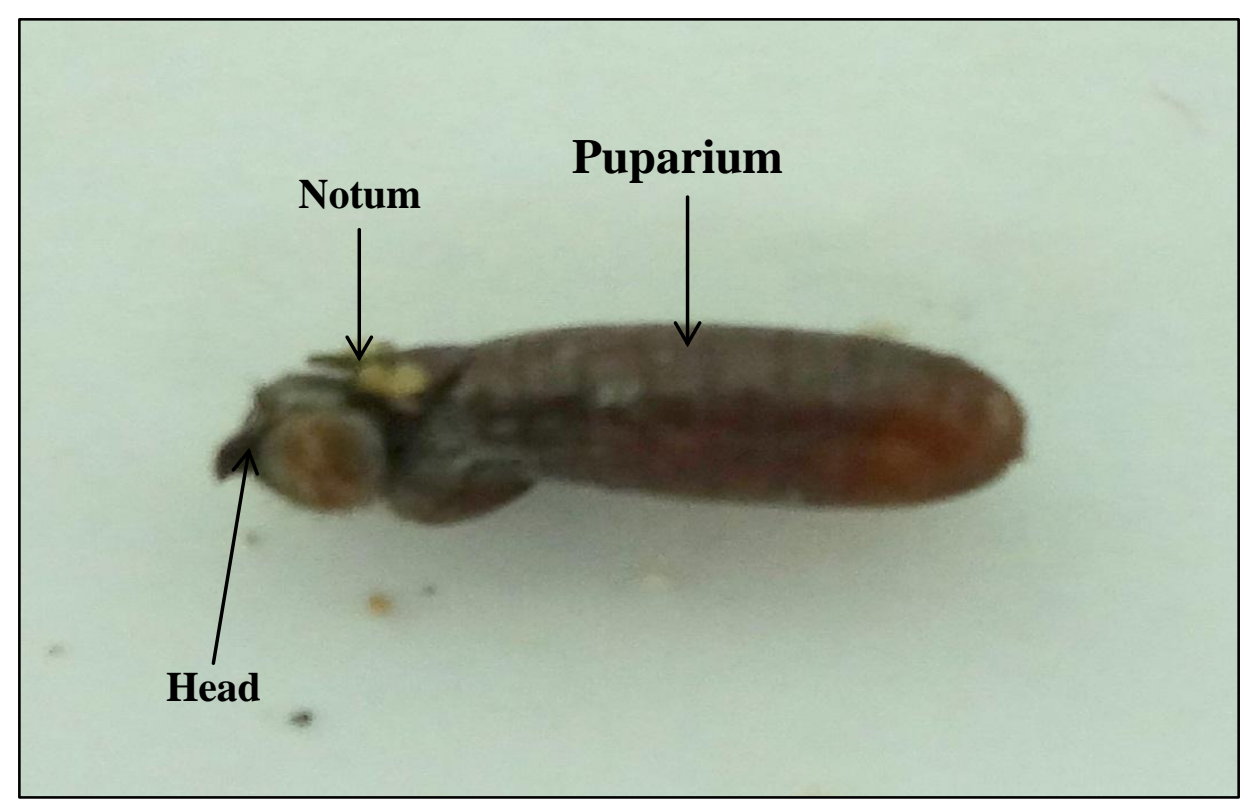

Fig. (6): Showing the dead adult during emergence results from shock. 


\section{Histological results}

The main effect of electrical shock on the heart structure where the wall was broken down and the bloods undergo the thrombosis inside the lumen in case of scatteredmasses. Probably the wall in some specimens exploded from one side. Plate (A)

While a severe effects on the alary muscles caused thedestroyed of muscle fibers and the fibers aggregated each on otherin agglutinated Phenom- enon. Plate (B).

The plasma of haemocoel also affected in abnormal case of particles which take the fusiform, triangular shape with few elongated or irregular, on a result of electrical shock of haemocoel.

Plate $(\mathrm{C})$.

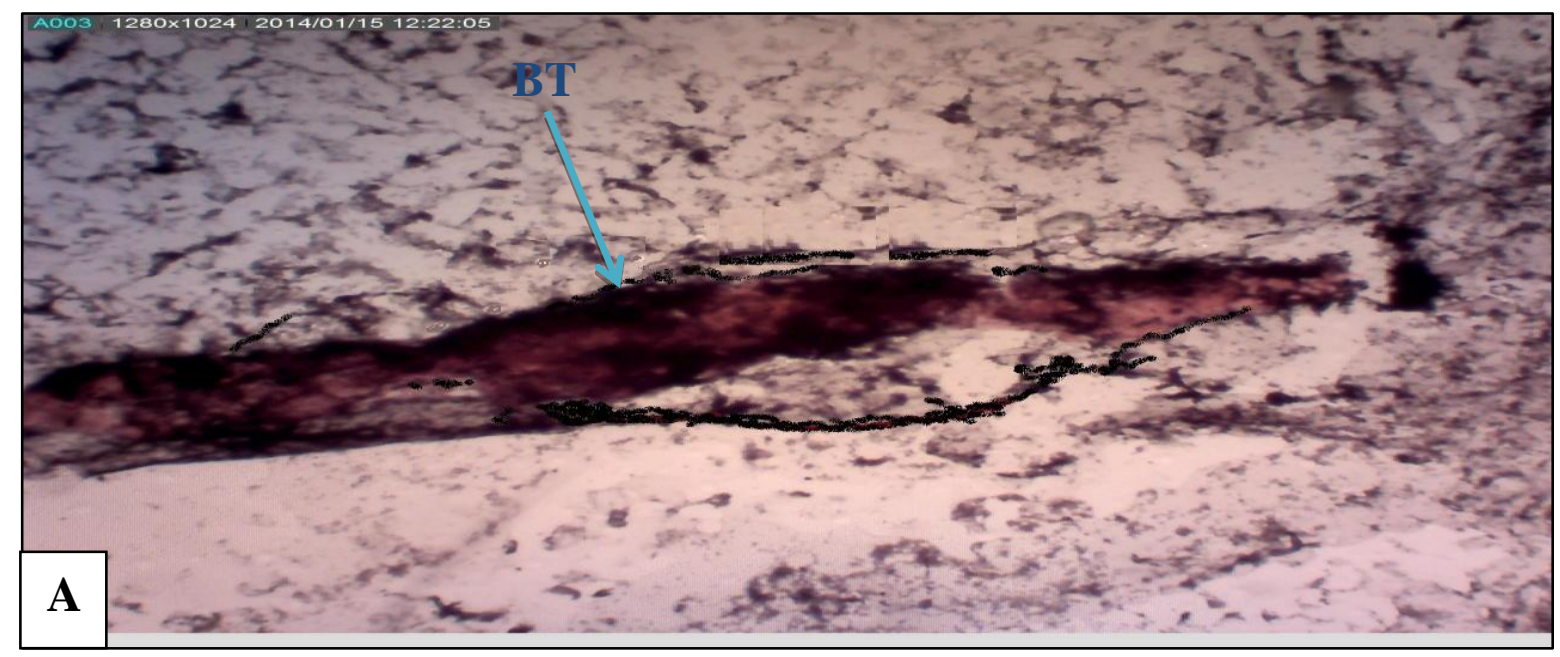

BT= Blood Thrombosis

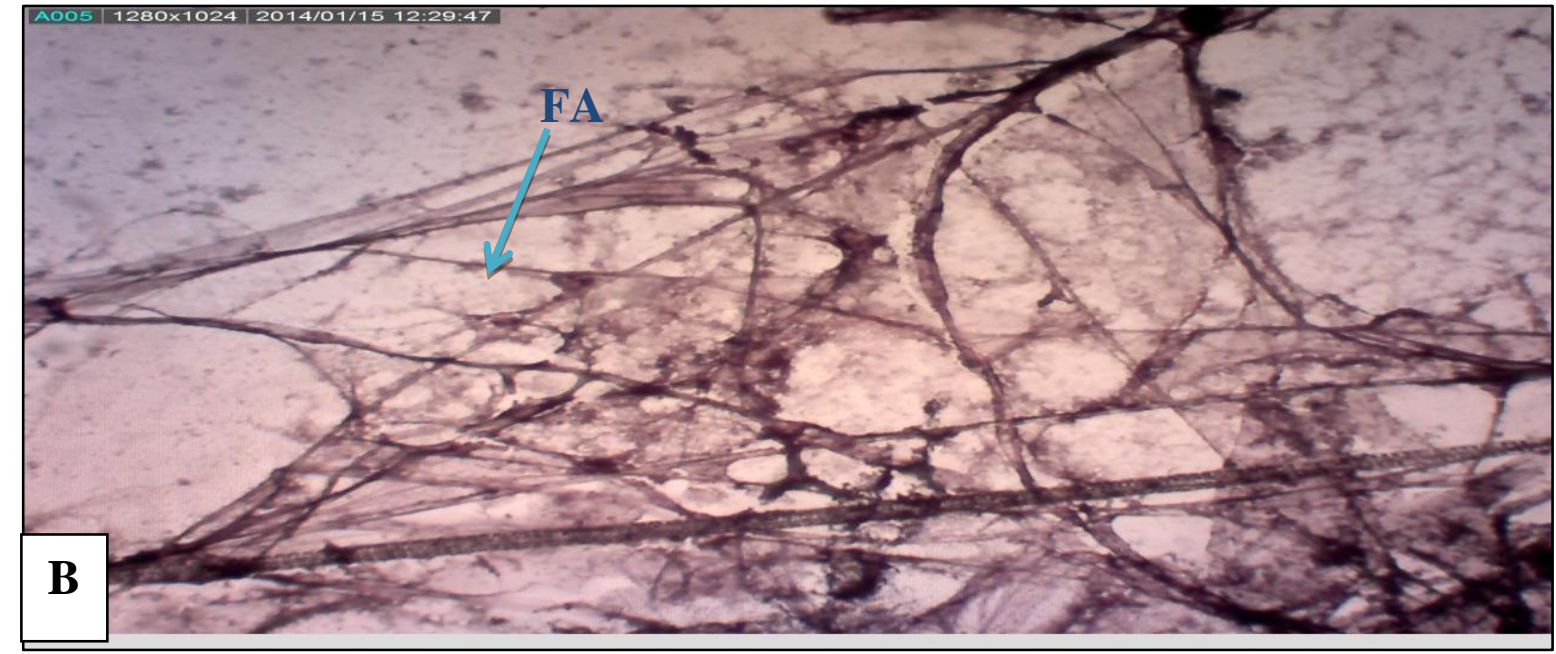

Fibers Aggregated 


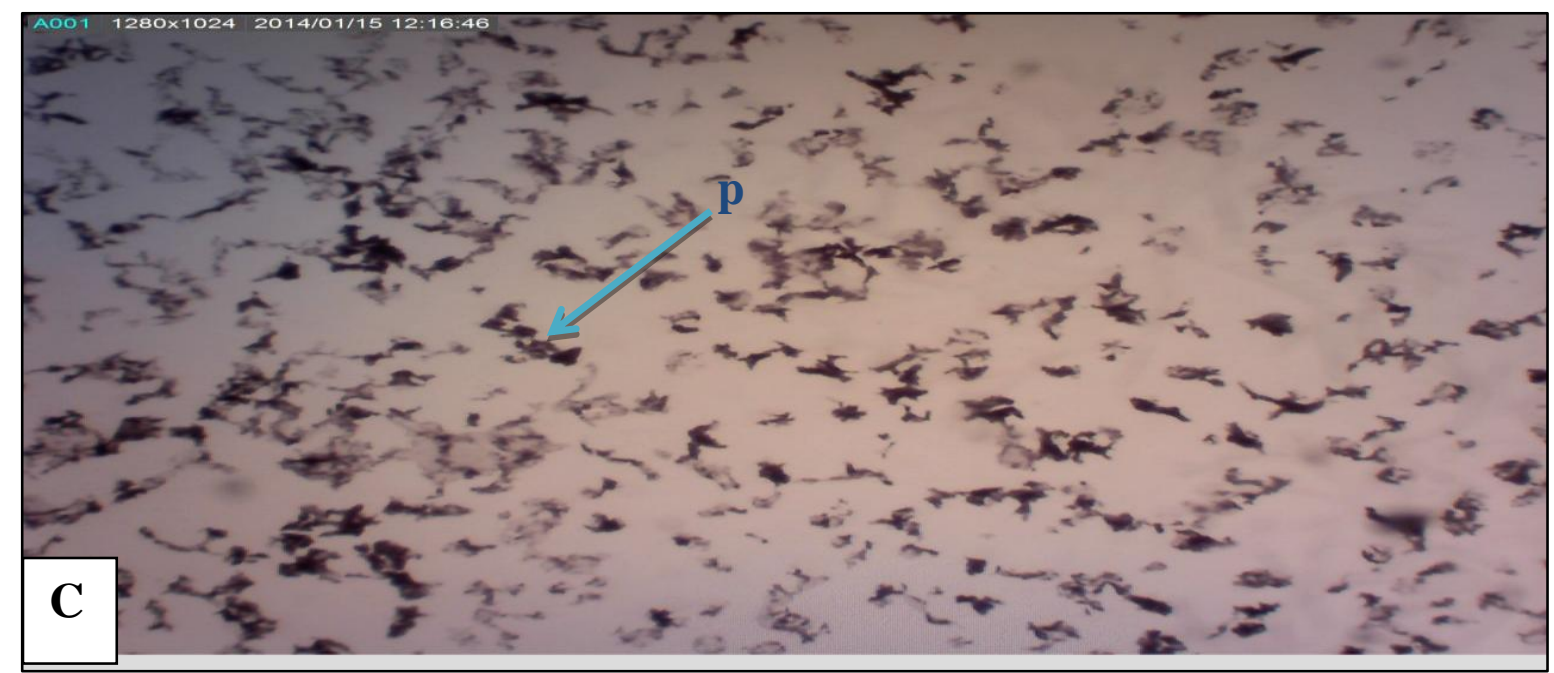

$\mathbf{P}=$ Various shapes of Particles(haemocoel contents)

40X

\section{REFERENCES}

- Gurr, G.T. (1963). Biological staining methods. Remoford RMT. IHA. England. $7^{\text {th }}$ ED. PP116.

- Kence, M. and Kence, K. (1993). Control of insecticides resistance in laboratory population of house fly (Diptera: Muscidae). J. Econo. Entomo. 86:189-194.

- Kristensen, M. , Jespersen, J.B. and Knorr, M. (2004). Cross-resistance potential of fipronil in Muscadomestica. Pest Manage Sci. 60:894-900.

- Mahmoud, T.T. (1985). The haemocytes and heart activity of Episyrphusbalteatus Deg. (Syrphidae :Diptera) and their response to environmental factors. Ph. D. Thesis, Univ. of Newcastle Upon Tyne England, pp.312.

- Mahmoud, T.T. (1991). Taxonomical and Physiological studies on syrphid flies in Iraq. Derassatsupl. B: 116-125. Jorden.

- Mahmoud, T.T. (2012). "Insect technology “. $1^{\text {st }}$ ed. Univ. press. Dohuk, pp.468.

- Nmorsi OPG, Agbozele G, Ukwandu NCD. (2007).Some aspects of epidemiology of filth flies: Muscadomestica, Muscadomesticavicina, Drosophilia melanogaster and associated bacteria pathogens in Ekpoma, Nigeria. VectorBorne Zoonotic Dis. Vol.7. No. (2):107-117.

- Pantin, C.F.A. (1964) Notes on microscopic Techniques for zoologists. $6^{\text {th }}$ ed. Cambridge univ. press. pp.77.
- Patricia, L.S. and Claudio, S. F. (2007). House fly (Muscadomestica L.) (Diptera: Muscidae) Development in different types of manure. Chilean J Agric Res. 68:192-197.

- Sanchez, H. (1998). Common house fly Muscadomestica L. Featured creature; Univeristy of Florida, Publication. pp.6.

- Sanchez-, H. and Capinera, J. L., 2008. Housefly. University of Florida, IFAS Featured Creatures.Publication EENY. No. (48):

- Sharififard, M.,Mossadegh, M.S. and Vazirianzadeh, B. (2012). Effects of temperature and humidity on the pathogenicity of the entomopathogenic fungi in control of the house fly, Muscadomestica L. (Diptera:Muscidae) under laboratory conditions. J. of Entomol.9: 282-288.

- Steel, R.G.D. and Torric, J.H. (1980). Principles and Procedures of Statistic. $2^{\text {nd }}$ Ed. Mc. Graw-Hill Company. Inc. London.

- Sumitomo Chem. Co. (1997). (Cited in saleh, 1996). Rearing methods of insect pests. Dept. Pesticide Res. Lab. Tokyo. p.7.

- Tawfik, M.F.S., Azab, A.K. and Awadallah, K.T. (1974). Studies on the life-history and description of the immature from of the EgyptinaphidophagousSyrphus corolla Fabr. Bull. Soc. Ento. Egypt.116.

- Wikipedia, (2011). The Free Encyclopedia. Housefly. 